\title{
Will the Real Bots Stand Up?
}

Stan Kelly-Bootle, Author

W hen asked which advances in computing technology have most dazzled me since I first coaxed the Cambridge EDSAC $1^{1}$ into fitful leaps of calculation in the 1950s, I must admit that Apple's iPod sums up the many unforeseen miracles in one amazing, iconic gadget. Unlike those electrical nose-hair clippers and salt 'n' pepper mills (batteries not included) that gather dust after a few shakes, my iPod lives literally near my heart, on and off the road, in and out of bed like a versatile lover-except when it's recharging and downloading in the piracy of my own home. ${ }^{2}$

I was an early iPod convert and remain staggered by the fact that I can pop 40 GB of mobile plug-and-play music and words in my shirt pocket. I don't really mind if the newer models are $80 \mathrm{~GB}$ or slightly thinner or can play movies; $40 \mathrm{~GB}$ copes easily with my music and electure needs. Podcasts add a touch of potluck and serendipity-doo-dah. Broadcasts from the American public radio stations that I've missed since moving back to England now reach my iPod automatically via free subscriptions and Apple's iTunes software. I've learned to live with that pandemic of "i-catching" prefixes to the point where I've renamed Robert Graves's masterwork "iClaudius," but I digress.

The functional "completeness" of the audio iPod stems from its ideal marriage of hardware and software. The compactness is just right, respecting the scale of human manipulations. The Dick Tracy wristwatch vade mecum failed through over-cram and under-size. The iPod succeeds with a legible alphanumeric screen and that senile-proof, uncluttered, almost minimal, click-wheel user interface. This avoids the input plague of most portable gadgets such as phones, calculators, and PDAs: the minuscule keyboards and buttons. I hasten to deflect the wrath of my daughter-in-law Peggy Sadler and all who have mastered and swear by the Palm Pilot stylus! The click wheel offers circular, serial access to and selection of your titles, but that's a decent compromise when you ponder the problems of searching by keywords. Spoken commands remain, as always, waiting for the next reassuring "breakthrough." I'll return anon to other Next-BigFix-Release promises.

\section{From EDSAC \\ to iPod-}

PREDICTIONS ELUDE US

Meanwhile, adding stilllife pictures, such as cover art, may retain the iPod's simple "completeness," but pushing the device to

TV seems to me to break the spell of sound gimcrackery [sic]. Peering at tiny moving pictures is a pointless pain, whereas even modestly priced earphones provide the superb hi-fi we used to dream about when growing up.

The near-exponential improvement of every computing power-performance parameter-physical size, clock speed, storage capacity, and bandwidth, to name the obvious features-is now a cliché of our fair trade. Yet even my older readers ${ }^{3}$ may need reminding just how bleak things were almost 60 years ago as the world's first stored-program machine (note the Cambridge-chauvinistic singular) moved into action.

The house-size EDSAC was effectively a single-user personal computer-a truly general computing factotum, but as Rossini's Figaro warns: Ahime, che furia! Ahime, que folla! Uno alla volta, per carità! (Heavens, what mayhem! Goodness, what crowds! One at a time, for pity's sake!)

Originally (1947) EDSAC boasted [sic] 512 words of main memory stored in 16 ultrasonic mercury-delay-line tanks, cleverly known as "long" tanks because they were longer than the short tanks used for registers. On the bright side, as we used to quip, each of the 512 words was 18 bits! Forget the word count, feel the width! Alas, for technical reasons, only 17 of the 18 bits were accessible. By 1952, the number of long tanks had doubled, providing a dizzy total of 1-KB words. Input/output was via fivetrack paper tape, which therefore also served as mass [sic again] storage. Subject only to global timber production, one might see this as virtually unlimited mass storage, although access was strictly slow-serial via 20-charactersper-second tape readers and 10-characters-per-second teletype printers. (By 1958, with EDSAC 2 taking over, paper tape and printer speeds had risen and magnetic tapes had become the standard backup and mass storage medium.)

Although hindsight and nostalgia can distort, one still looks back with an old soldier's pride at the feats achieved Continued on page 52 


\section{Continued from page 56}

with what seem now to be ridiculously frugal resources. Maurice Wilkes, David Wheeler, and Stan Gill had written the first book on programming. ${ }^{4}$ This revered, pioneering trio are generally acknowledged as the co-inventors of the subroutine and relocatable code. As with all the most sublime of inventions, it's difficult to imagine the world without a call/return mechanism. Indeed, I meet programmers, whose parasitic daily bread is earned by invoking far-flung libraries, who have never paused to ponder with gratitude that the subroutine concept needed the brightest heaven of invention. Although no patents for the basic subroutine mechanism were sought (or even available) back then, a further sign of changing times is that patents are now routinely [sic] awarded for variations on the call/return mechanism, as well as for specific subroutines. ${ }^{5}$

David Wheeler died suddenly in 2004 after one of his daily bicycle rides to the Cambridge Computer Labs. It's quite Cantabrigian to "die with your clips on." I had the sad pleasure of attending David's memorial service and learning more of his extensive work in many areas of computing. ${ }^{6}$

Other innovations from the Cambridge Mathematical Laboratory in the early 1950s included Wilkes's paper introducing the concept of microprogramming. On a more playful note was the XOX program written by my supervisor A. S. (Sandy) Douglas. This played (and never lost!) tic-tac-toe (also known as OXO)—a seemingly trivial pursuit, yet one with enormous, unpredicted consequences. XOX was the very first computer game with an interactive CRT display, the challenge being not the programming logic, of course, but the fact that the CRT was designed and wired for entirely different duties. Little could anyone guess then that games and entertainment would become the dominant and most demanding applications for computers. Can anyone gainsay this assertion? One would need to add up all the chips, MIPS, terabytes, and kid-hours (after defining kid), so I feel safe in my claim. Discuss! If you insist, I can offer a weaselly cop-out: Games and entertainment are now among the most dominant and demanding applications for computers.

Cue in some computer-historic Pythonesque clichés: "We had it tough in them days, folks. The heat, mud, dust, and flies. Try telling the young'uns of today-they just don't believe yer. And did I mention the heat? 3,000 red-hot Mullard valves. All of us stripped down $t^{\prime}$ waist-even $t^{\prime}$ men!" Then an older old soldier would intervene: "512 words? You were lucky! All we had were two beads on a rusty abacus!" More ancient cries of disbe- lief: "An abacus? Sheer luxury! We had to dig out our own pebbles from $t^{\prime}$ local quarry. We used to dream of having an abacus..."

In truth, adversity did bring its oft-touted if not so sweet usages. Programming at the lower levels with limited memory constantly "focused the mind"-you were nearer the problem, every cycle had to earn its keep, and every bit carry [sic!] its weight in expensive mercury, as it were. The programming cycle revolved thus: handwrite the code on formatted sheets; punch your tape on a blind perforator (the "prayer" method of verification was popular, whence quips about the trademark Creed); select and collate any subroutines (the library was a set of paper tapes stored in neat white boxes); wait in line at the tape reader (this was before the more efficient "cafeteria" services were introduced); then finally collect and print your output tape (if any). All of which combined to impose a stricter discipline on what we now call software development. More attention perhaps than in these agile, interactive days was given to the initial formulation of the program, including "dry runs" on Brunsviga hand calculators. Indeed, the name of our discipline was numerical analysis and automatic computing, only later to be called computer science. ${ }^{7}$

EDSAC designer Professor (now Sir) Maurice Wilkes was quoted by the Daily Mail, October 1947:

"The brain will carry out mathematical research. It may make sensational discoveries in engineering, astronomy, and atomic physics. It may even solve economic and philosophical problems too complicated for the human mind. There are millions of vital questions we wish to put to it."

A few years later, the Star (June 1949) was reporting: "The future? The 'brain' may one day come down to our level and help with our incometax and bookkeeping calculations. But this is speculation and there is no sign of it so far."

Allowing for journalistic license, one can spot early differences between how computing was expected to evolve and how, in fact, things turned out. The enormous impact on scientific research did come about and continues to grow, but the relative pessimism about commercial applications quickly vanished. Indeed, soon after the June 1949 quote ("no sign of it so far"), the UK's leading caterers, food manufacturers, and tea-shop chain, J. (Joe) Lyons \& Co., embarked on its LEO (Lyons Electronic Office) project, a business computer based directly on Wilkes's EDSAC designs (with appropriate financial support). I recall visits by the Joe Lyons "suits," who 
explained that there was more to their business computing needs than multiplying NumberOfBuns by UnitBunPrice. LEO was running complex valuation, inventory, and payroll applications by 1951, an important root of the global expansion of commercial IT subsequently dominated by IBM.

I now move from praising the pleasantly unpredicted iPod-in-my-pocket to complaining about the overconfident predictions that continue to elude us. Otherwise, this column will fail to qualify as "curmudgeonly." Reconsider the 1947 proposition: "It [meaning IT!] may even solve economic and philosophical problems too complicated for the human mind." One can agree that many complicated "economic" problems have succumbed. Here one must think beyond cutting payroll checks and the inventory control of tea cakes. Although such tasks can be quite complex because of sheer size and the quirks of a volatile real-world rule-set, they remain essentially mechanizable given the certifiable [sic] patience of nitpicking programmers. ${ }^{8}$

Moving to the wider field of "economic" problems that are truly "too complicated for the human mind," we can acknowledge the progress made in the computer-modeling of such domains as global trade, energy consumption, and climate change. These systems stretch the normal physical laws of cause and effect by having to cope with chaos (the susceptibility to small input changes and measurement accuracies) and the nondeterministic influences of human behavior. Nevertheless, these models are useful in testing possible outcomes for given policy decisions.

Interestingly, Professor Steve Rayner (director of the James Martin Institute, Oxford University) calls the global environmental problem "wicked," a technical term for those complex problems that demand "clumsy" solutions. Clumsy is also a technical term! Briefly, clumsy solutions combine the diverse solutions hinted at by the various competing models in an undogmatic way (see http://www.unsw.edu.au/news/pad/articles/2006/jul/jack_ beale_lecture.html). To this extent, the prediction that computers "may even solve economic problems too complicated for the human mind" is unfolding with promise, although the emphasis should really be on "helping us to solve."

Finally, what can we say about the 1947 hope that computers "may even solve philosophical problems too complicated for the human mind." Je dis que NON! The $\mathrm{AI}$ and robotics dreams continue to frustrate us even in the reduced realm of simulating what all human minds (and bodies) do naturally as a matter of course without any "complicated" introspection! In particular, I mean the sine-qua-non acquisition and command of natural language. The claimed progress certainly excites some Aivatarians (the folks who apply AI techniques to construct artificial avatars). Chomsky's analogy is telling: The long-jumpers increase their leaps each year, and claim that one day soon they will achieve bird-like flight. Or the parrots, taught to... er... parrot an increasing number of words, will one day (to paraphrase Bertrand Russell) tell you that their parents were poor but honest.

The ACM TechNews (Oct. 20, 2006) reports the creditable achievements of the aivatar (AI avatar) George, programmed by Rollo Carpenter of Televisual. George is a chatbot, a term adding to the glut of bots, derived from the Czech Karel Câpek's play R.U.R. (Rossum's Universal Robot). Robot (coined by Câpek's brother) comes from the Slavonic root for work, but we must not overlook the political satire: robota meant statute labor in the days of

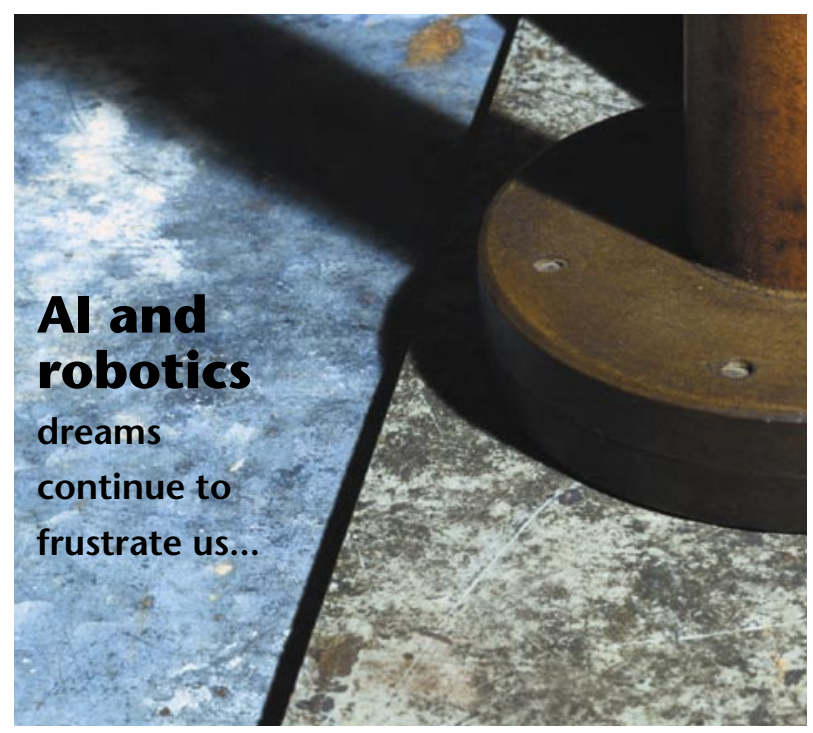

Uncle Joe. We now have as many bots in the computer laxicon as wares. Thus, genetically modified veggies are grobots, and humans are knobots (compare with wetware for that mushy stuff between our ears).

George is said to "speak" some 40 languages, having had more than 11 million "conversations" with human online text messages via http://www.jabberwacky.com (note the deliberate variant spelling from Lewis Carroll's poem "Jabberwocky." The hint may be that WACI is emerging as an acronym for wild and crazy ideas).

My own brief exchange with George reminds me of those early versions of Doctor but clearly with the richer range you might expect from a larger database. George's 
replies lack any real signs of human intelligence. Discussing Democratic presidential candidates (George's idea), I entered "Hillary Clinton." George replied, "Hilary Clinton is a senator." I said, "She's also a candidate for president." George replied, "Oh yes, I know!!!” But when I asked, "Is she Hilary or Hillary?", George answered, "This does not make sense-how about math?" I said, "Nyet," and George answered: "You're right, that's Russian."

The site has a disclaimer: "Jabberwacky learns the behavior and words of its users. It may use language and produce apparent meanings that some will consider inappropriate. Use this site with discretion, and entirely at your own risk."

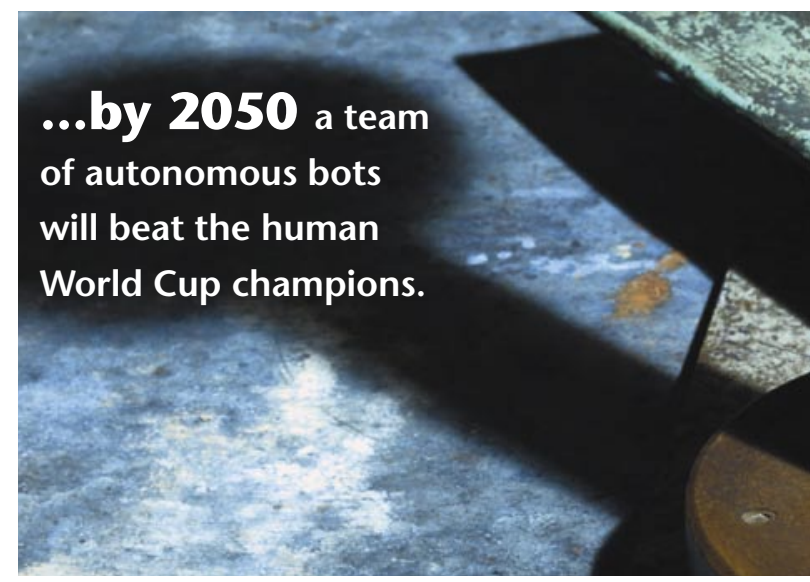

The point has long been made that human knowledge and learning relies deeply on our having a corporeal entity able to explore three-dimensional space and some cognitive "devices" to acquire the notions of both place and time. Chatbots that reside in static hardware are rather limited in this respect. Hence the need for a mobile bot, whether it has humanoid features such as Rossum's original robots or not. From "embedded systems" to "embodied"?

For limited, repetitive actions in tightly controlled environments, tremendous progress has been made, as in motor-car assembly. As a devout soccer fan, I'm intrigued by the possibilities of two teams of 11 robots playing the Beautiful Game. In 1997, Hiroaki Kitano launched the annual Robot World Cup, or RoboCup for short. ${ }^{9}$ (The name Ballbot has been taken up elsewhere for a robot that moves around rather like a gymnast walking while balanced on a large sphere; see http://www. post-gazette.com/pg/06235/715415-96.stm.) By 2002, 29 different countries had entered the RoboCup staged in Fukuoka, Japan, attracting a total audience of 120,000 fans. Peter Seddon describes the game between the Baby
Tigers (Japan) and the Dirty Dozen (Germany) as "looking remarkably like a contest between toasters on wheels, while the Four-Legged League (RoboMutts) appeared to spend most of the time sniffing each other's shorts."

Kitano remains optimistic that by 2050 a team of autonomous bots will beat the human World Cup Champions. That's a prediction that's difficult to gainsay. Kitano points out that 50 years after EDSAC, the IBM Deep Blue beat world chess champion Garry (or some prefer Gary) Kasparov. Seddon argues that playing a symbolic "computable" game like chess cannot be compared with the physical complexities of soccer, where the rules appear simple but defy algorithmic precision. "He was bleedin' off-side!" "Oh no, he bleedin' wasn't!"

Seddon reckons that the chances of Kitano's prophesy coming true are about the same as Beckham ever becoming world chess champion. That honor, by the way, has just been achieved by the Russian Vladimir Kramnik but not without some all-too-human, sordid altercations. His rival, the Bulgarian Veselin Topalov, objected to Kramnik's frequent trips to the restroom (or, in chess notation, $\mathrm{K} \times \mathrm{P}$ ?). The ultimate insult was that Kramnik had been consulting a computer hidden in the Gents. This was convincingly disproved, but one further irony ensued. Since the normal games ended in a points tie, a soccerlike extra-time had to be played: four games of nail-biting rapid play, which, to the relief of all fair-chess lovers, was won by Kramnik. Q

\section{REFERENCES}

1. You, too, can relive those heroic days. Martin Campbell-Kelly (no relation) of Warwick University offers an EDSAC simulator for the PC and Mac; http://www.dcs. warwick.ac.uk/ edsac/Software/EdsacTG.pdf. This site will also point you to the vast EDSAC bibliography.

2. I'm lying for a cheap laugh. In fact, I've never knowingly stolen a file of any kind. As a member of ASCAP (American Society of Composers, Authors, and Publishers), I urge you all to obey the IP (intellectual property) protocols.

3. EOF, possibly overloaded from EndOfFile to ExtremelyOldFart, started life as plain OF (OldFart) in the Jargon File and subsequent versions of the Eric Raymond/Guy Steele Hacker's Dictionary. In the 1980s OF was generally applied (with pride or sarcasm) to those with more than about 25 years in the trenches. It now seems appropriate to define EOFs by stretching the time served to "more than about 50 years."

4. Wilkes, M. V., Wheeler, D. J., Gill, S. 1951. The Preparation of Programs for an Electronic Digital Computer. 
New York: Addison-Wesley.

5. For the effective nullification in 1994 of the Supreme Court's 1972 Gottschalk v. Benson decision, which had excluded mathematical algorithms from patents applications, see http://www.unclaw.com/chin/scholarship/software.htm. Andrew Chin discusses the vital topic of computational complexity and its impact on patent-law complexity! Claims made for "effective" algorithms can run afoul of well-known computer-scientific theorems.

6. http://www.cl.cam.ac.uk/UoCCL/misc/obit/wheeler. html.

7. Professor P. B. Fellgett once asked the possibly rhetorical question, "Is computer science?" Professor Dijkstra was dubious, posing the counter-riddle, "Is typewriter science?" thereby proving the correctness of the name "computing science."

8. Readers may have their own counter-anecdotes where apparently trivial business functions turn out to be provably noncomputable. I exclude the epistemological problems of Lex Coddonis: the axioms for normalizing a 100-percent-conforming relational database. I recall programming a UK County Council payroll on the IBM 650 , where the police were given a supposedly tax-free clothing allowance that another rule declared taxable, leading to a later refund of the tax paid that was itself taxed and later refunded, ad almost infinitum.

9. Seddon, P. 2005. The World Cup's Strangest Moments. Chrysalis Books.

\section{LOVE IT, HATE IT? LET US KNOW}

feedback@acmqueue.com or www.acmqueue.com/forums

STAN KELLY-BOOTLE (http://www.feniks.com/skb/; http:// www.sarcheck.com), born in Liverpool, England, read pure mathematics at Cambridge in the 1950s before tackling the impurities of computer science on the pioneering EDSAC I. His many books include The Devil's DP Dictionary (McGrawHill, 1981), Understanding Unix (Sybex, 1994), and the recent e-book Computer Language-The Stan Kelly-Bootle Reader (http://tinyurl.com/ab68). Software Development Magazine has named him as the first recipient of the new annual Stan Kelly-Bootle Eclectech Award for his "lifetime achievements in technology and letters." Neither Nobel nor Turing achieved such prized eponymous recognition. Under his nom-de-folk, Stan Kelly, he has enjoyed a parallel career as a singer and songwriter.

(c) 2006 ACM 1542-7730/06/1200 $\$ 5.00$ 